\title{
Development and validation of a nomogram to predict cancer-specific survival of uveal melanoma
}

\author{
Qiaozhu Zeng ${ }^{1,2}$, Yuou Yao ${ }^{1,2}$ and Mingwei Zhao ${ }^{1,2^{*}}$
}

\begin{abstract}
Background: Uveal melanoma (UM) is a rare but aggressive cancer, which is the most common primary intraocular malignancy in adults. We aimed to develop and validate a competing risk nomogram to predict cancer-specific survival (CSS) of patients with UM, as well as compare its prognostic value with that of the American Joint Committee on Cancer (AJCC) staging system.

Methods: Data of patients diagnosed with UM from 2010 to 2015 were identified from the Surveillance, Epidemiology, and End Results (SEER) database. We extracted and integrated significant prognostic factors based on competing risk regression to build a nomogram. The nomogram with an online prediction version was also created. The performance of the nomogram was evaluated using Harrell's concordance index (C-index) and calibration plots. Receiver operating characteristic (ROC) curve was carried out to estimate clinical applicability of the model. Improvements in the predictive accuracy of our new model compared with AJCC staging system were estimated by calculating the relative integrated discrimination improvement (IDI) and the net reclassification improvement (NRI).

Results: A total of 839 eligible patients with primary UM were randomly assigned to a training cohort $(588,70 \%)$ and a validation cohort (251,30\%). Age, histological type, T stage and M stage were independent prognostic factors to predict CSS of UM and were incorporated in the nomogram. The calibration plots indicated that the 3-and 5-year CSS probabilities were consistent between the nomogram prediction and the actual observation. The $\mathrm{C}$-index for this model was 0.778 (95\% Cl:0.756-0.800) and 0.786 (95\% Cl: 0.749-0.816) in the training cohort and validation cohort. Areas under the curve (AUCs) were $0.814,0.771$, and 0.792 in the training cohort, $0.788,0.781$ and 0.804 in the validation cohort, respectively. The NRI value in AJCC staging system was -0.153 ( $95 \% \mathrm{Cl}-0.29--0.041)$ for 3 years of follow-up and -0.276 (95\% Cl $-0.415--0.132)$ for 5 years of follow-up. The IDI values for 3 and 5 years of follow-up in the AJCC staging system were $-0.021(P=0.076)$ and $-0.045(P=0.004)$, respectively.
\end{abstract}

Conclusions: We have developed and validated a competing risk nomogram to reliably predict cancer-specific survival of patients with UM. This convenient tool may be useful for evaluating cancer-specific prognosis.

Keywords: Uveal melanoma, SEER, Cancer-specific survival, Nomogram

\footnotetext{
* Correspondence: drzmwpku@163.com

'Department of Ophthalmology, Eye Diseases and Optometry Institute,

Peking University People's Hospital, No. 11 Xizhimen South Street, Beijing,

Xicheng District, China

${ }^{2}$ Beijing Key Laboratory of Diagnosis and Therapy of Retinal and Choroid Diseases, College of Optometry, Peking University Health Science Center, Beijing, China
}

\section{BMC}

(c) The Author(s). 2021 Open Access This article is licensed under a Creative Commons Attribution 4.0 International License, which permits use, sharing, adaptation, distribution and reproduction in any medium or format, as long as you give appropriate credit to the original author(s) and the source, provide a link to the Creative Commons licence, and indicate if changes were made. The images or other third party material in this article are included in the article's Creative Commons licence, unless indicated otherwise in a credit line to the material. If material is not included in the article's Creative Commons licence and your intended use is not permitted by statutory regulation or exceeds the permitted use, you will need to obtain permission directly from the copyright holder. To view a copy of this licence, visit http://creativecommons.org/licenses/by/4.0/. The Creative Commons Public Domain Dedication waiver (http://creativecommons.org/publicdomain/zero/1.0/) applies to the data made available in this article, unless otherwise stated in a credit line to the data. 


\section{Background}

Uveal melanoma (UM) is the most common primary intraocular malignancy in adults, with the mean ageadjusted incidence of 5.1 per million in the USA [1], representing up to $85 \%$ of ocular melanomas [2]. UM is a relatively rare but aggressive cancer, accounting for 3$5 \%$ of all melanoma cases [2]. Five-year survival rates of UM were reported to be stable as approximately $80 \%$ in the past three decades, however, up to $50 \%$ of patients may develop metastases [3, 4], Moreover, about $50 \%$ of patients with uveal melanoma might succumb to metastasis within 10 years of diagnosis. The prognosis of uveal melanoma was reported to be predicted by several independent factors, including clinical, histopathological, cytogenetic, and transcriptomic markers.

Although there have been a few articles reporting the incidence, treatment and survival of UM, the clinicopathological characteristics and prognosis of UM still need further study because of its low prevalence rate and limited cases in previous studies. In addition, no ideal prediction model for prognosis of UM was yet identified, especially for the cancer-specific survival (CSS). A nomogram is a convenient tool to predict and quantify the probability of a patient developing a certain clinical event, which was valuable for clinical decision making and risk stratification. On the other hand, the staging system for UM was changed to American Joint Committee on Cancer (AJCC) seventh edition since
2010, incorporating significant changes into the T-staging $[5,6]$. Therefore, based on a large-scale population from the Surveillance, Epidemiology, and End Results (SEER) database, we are the first to develop and validate a competing risk nomogram to predict CSS of patients with $\mathrm{UM}$, as well as compare its prognostic value with that of the AJCC staging system.

\section{Methods}

\section{Data source and patient selection}

The SEER database consists of 18 population-based registries covering nearly $28 \%$ of the US population. SEER*Stat software version 8.3.6 was used to select patients from the Incidence-SEER 18 Regs Research database based on our application on November, 2020 to build the cohort. The inclusion criteria were as follows: 1) diagnosed from 2010 to 2015; 2) pathologically confirmed UM; 3) the International Classification of Diseases for Oncology-3 (ICD-3) histology code (morphology code 8720-8790); 4) ICD-O-3 site code of C69.3 (choroid) and C69.4 (ciliary body and iris); 5) only one malignant primary tumor of UM; 6) patients with active follow up and age of 18 or more than 18 . We excluded patients with incomplete survival data or survival time of fewer than 1 month, unknown AJCC stage (according to the 7th edition of AJCC TNM classification), unknown laterality and race. The flow chart of patient selection was indicated in Fig. 1.

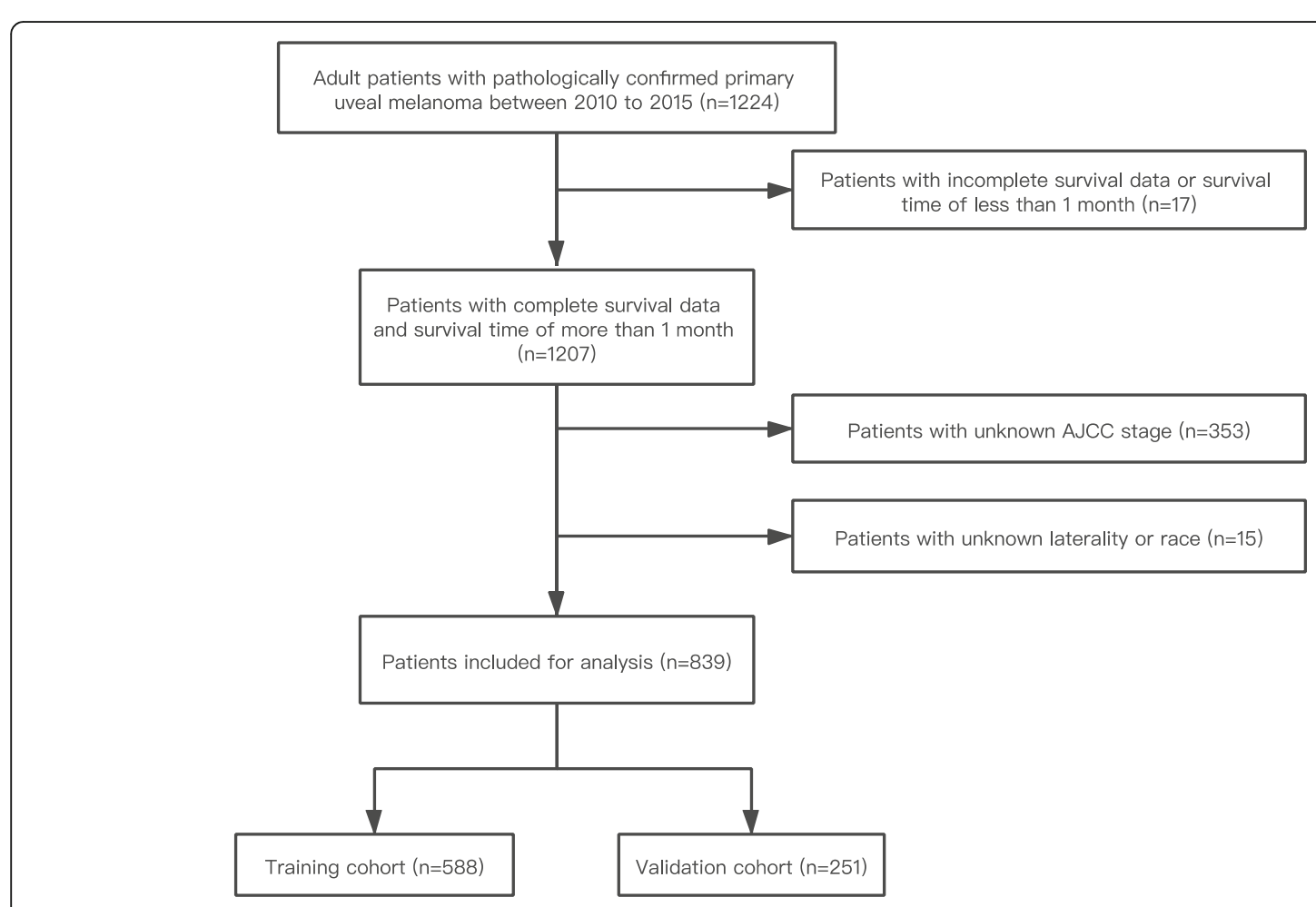

Fig. 1 Flow chart of cases selection from SEER database 


\section{Study variables}

Several variables were extracted: baseline demographics (year of diagnosis, age at diagnosis, sex, race, insurance status, marital status), tumor features (primary site, laterality, $\mathrm{T}$ stage, $\mathrm{N}$ stage, $\mathrm{M}$ stage, AJCC stage, histological type, metastasis at diagnosis), therapy (surgery, radiation, chemotherapy), and survival variables (months of survival, vital status, cause-specific classification of death). CSS was the study endpoint and it was defined as the time from diagnosis to death attributed to uveal melanoma.

\section{Statistical analysis}

In pursuit of full use of our data for constructing the predictive model, as well as keeping a considerable number of patients for its validation, we randomly allocated 70 and $30 \%$ of the enrolled eligible patients to the training cohort $(n=588)$ and validation cohort $(n=251)$, respectively, which was consistent with the assignment in some previous studies $[7,8]$.

The optimal cutoff values for age range were determined using the $\mathrm{X}$-tile software in survival analyses. Patient characteristics were analyzed by descriptive methods, with standard summary statistics including mean (S.D.), median, interquartile range (IQR), and proportions. We performed the Student's t test for differences for continuous, normally distributed data; continuous, non-normally distributed data were analyzed by the Mann-Whitney test. Categorical variables were processed by $\mathrm{X} 2$ or Fisher's exact tests.

Fine and Gray's competing risks regression model was applied to identify predictors of CSS. We incorporated factors with $P$-value $<.05$ identified in univariable analyses to develop multivariable regression models. Competing-risk regression was used to estimate the subhazard ratio (SHR) and evaluate the association between variables and risk of CCS. Death due to other causes was considered a competing event [9]. Cumulative incidence functions (CIF) for the competing event were calculated based on the competing risk methodology [10].

A nomogram was constructed based on the result of the multivariable analysis. The nomogram was subjected to 500 bootstrap resamples for internal validation with the training cohort and external validation with the validation cohort. Performance of the nomogram to predict CSS was evaluated with discrimination and calibration. The Harrell's concordance index (C-index) was calculated to measure the discrimination ability [11], which ranges from 0.5 to 1.0 , with 0.5 indicating random chance and 1.0 indicating a perfect ability to discriminate the outcome precisely [12]. The calibration was represented by a calibration curve at 3 and 5 years, comparing the predicted and observed probabilities of CSS. Receiver operating characteristic (ROC) curve was carried out to estimate clinical applicability of the model. Moreover, according to the cut-off value determined by the highest one-third of the total score calculated from the nomogram of the training cohort, all eligible patients were stratified into highand low-risk groups, and the cumulative incidence of cancer-specific mortality curves in patients with different therapies were plotted. Improvements in the predictive accuracy of our new model were estimated by calculating the relative integrated discrimination improvement (IDI) and the net reclassification improvement (NRI) [13].

We constructed and validated the nomogram by RStudio software (V. 1.2.5001). R project's mstate package and rms package were applied to build a nomogram, and risk Regression package was used to evaluate the performance of the nomogram. The nomogram with an online prediction version was created by DynNom package. Besides, we performed all statistical analyses by Stata/SE 15.0 (V.15.0; Stata, College Station, TX, USA), except for the development and validation of nomogram. All statistical tests were two-tailed. $P<0.05$ was considered to be statistically significant.

\section{Results \\ Patient characteristics}

A total of 839 eligible patients with primary UM were identified from the SEER database and included in the analysis. They were randomly assigned to a training cohort $(588,70 \%)$ and a validation cohort $(251,30 \%)$. The demographic, clinicopathological characteristics and treatment information of each cohort were shown in Table 1 . The median age at diagnosis of all patients were 60 years. There were $465(55.4 \%)$ males and $374(44.6 \%)$ females, and the majority of patients were white. Choroid was the common primary site of UM $(88 \%)$. All the patients had unilateral UM, with similar rates of left or right eye involvement. Median measured basal diameter of tumor was $12 \mathrm{~mm}$, with the median measured thickness of $5.4 \mathrm{~mm}$. Histological types mainly included spindle cell melanoma (17.2\%), mixed epithelioid and spindle cell melanoma (13.8\%), epithelioid cell melanoma (5.2\%) and others. The rate of metastasis to liver is $2 \%$, which was highest among the rate of metastasis to bone, lung and brain. Most of patients possessed localized $(89.6 \%)$ or regional (7.6\%) historic stage. More than a half of patients with UM received radiotherapy (59\%). Approximately $50 \%$ of patients underwent surgery, and only a small proportion of all patients were treated with chemotherapy (3\%).

The characteristics did not significantly differ between the training and validation cohorts. The follow-up time from diagnosis to CSS was 32 (IQR: 20-51) and 32 (IQR: 18-53) months in the two groups, respectively. In the training cohort, there were 104 cancer-specific deaths (17.7\%); in the validation cohorts, 55 cancer-specific deaths (21.9\%) were identified. 
Table 1 Demographic, clinicopathological characteristics and treatment information of all, training and validation cohort

\begin{tabular}{|c|c|c|c|c|c|}
\hline & & $\begin{array}{l}\text { All patients } \\
(n=839)\end{array}$ & $\begin{array}{l}\text { Training cohort } \\
(n=588)\end{array}$ & $\begin{array}{l}\text { Validation cohort } \\
(n=251)\end{array}$ & $P$-value \\
\hline Age, y, median (IQR) & & $60(51,69)$ & $60(52,69)$ & $60(51,68)$ & 0.492 \\
\hline \multirow[t]{3}{*}{ Age, $n(\%)$} & & & & & 0.484 \\
\hline & $\leq 58$ & $379(45.2)$ & $261(44.4)$ & $118(47.0)$ & \\
\hline & $>58$ & $460(54.8)$ & $327(55.6)$ & $133(53.0)$ & \\
\hline \multirow[t]{3}{*}{ Gender, $n$ (\%) } & & & & & 0.637 \\
\hline & Female & $374(44.6)$ & $259(44.0)$ & $115(45.8)$ & \\
\hline & Male & $465(55.4)$ & $329(56.0)$ & $136(54.2)$ & \\
\hline \multirow[t]{4}{*}{ Race, n (\%) } & & & & & 0.352 \\
\hline & White & $812(96.8)$ & $568(96.6)$ & $244(97.2)$ & \\
\hline & Black & $13(1.6)$ & $8(1.4)$ & $5(2.0)$ & \\
\hline & Other & $14(1.7)$ & $12(2.0)$ & $2(0.8)$ & \\
\hline \multirow[t]{4}{*}{ Marriage, $n(\%)$} & & & & & 0.188 \\
\hline & Married & $467(55.7)$ & $326(55.4)$ & $141(56.2)$ & \\
\hline & Unmarried & $296(35.3)$ & $202(34.4)$ & $94(37.5)$ & \\
\hline & Unknown & $76(9.1)$ & $60(10.2)$ & $16(6.4)$ & \\
\hline \multirow[t]{5}{*}{ Insurance, n (\%) } & & & & & 0.173 \\
\hline & Medicaid & $77(9.2)$ & $60(10.2)$ & $17(6.8)$ & \\
\hline & Insured & $721(85.9)$ & $497(84.5)$ & $224(89.2)$ & \\
\hline & Uninsured & $30(3.6)$ & $21(3.6)$ & $9(3.6)$ & \\
\hline & Unknown & $11(1.3)$ & $10(1.7)$ & $1(0.4)$ & \\
\hline \multirow[t]{3}{*}{ Primary site, $n(\%)$} & & & & & 0.679 \\
\hline & Chorioid & $738(88.0)$ & $519(88.3)$ & $219(87.3)$ & \\
\hline & Cilliary body and iris & $101(12.0)$ & $69(11.7)$ & $32(12.8)$ & \\
\hline \multirow[t]{3}{*}{ Laterality, n (\%) } & & & & & 0.886 \\
\hline & Left & $418(49.8)$ & $292(49.7)$ & $126(50.2)$ & \\
\hline & Right & $421(50.2)$ & $296(50.3)$ & $125(49.8)$ & \\
\hline \multirow[t]{5}{*}{ Histological type, $n(\%)$} & & & & & 0.563 \\
\hline & Spindle cell melanoma & $144(17.2)$ & $107(18.2)$ & $37(14.7)$ & \\
\hline & $\begin{array}{l}\text { Mixed epithelioid and spindle } \\
\text { cell melanoma }\end{array}$ & $116(13.8)$ & $78(13.3)$ & $38(15.1)$ & \\
\hline & Epithelioid cell melanoma & $44(5.2)$ & $29(4.9)$ & $15(6.0)$ & \\
\hline & Other & $535(63.8)$ & $374(63.6)$ & $161(64.1)$ & \\
\hline \multirow[t]{8}{*}{ Stage, $n(\%)$} & & & & & 0.480 \\
\hline & I & 159 (19.0) & $117(20.0)$ & $42(16.7)$ & \\
\hline & Ila & $260(31.0)$ & $180(30.6)$ & $80(31.9)$ & \\
\hline & $\| \mathrm{b}$ & $172(20.5)$ & $125(21.3)$ & 47 (18.7) & \\
\hline & IIla & $134(16.0)$ & $89(15.1)$ & 45 (17.9) & \\
\hline & $\| l l b$ & $74(8.8)$ & $52(8.8)$ & $22(8.8)$ & \\
\hline & IIlc & $16(1.9)$ & $12(2.0)$ & $4(1.6)$ & \\
\hline & IV & $24(2.9)$ & $13(2.2)$ & $11(4.4)$ & \\
\hline \multirow[t]{4}{*}{ T stage, $n(\%)$} & & & & & 0.976 \\
\hline & $\mathrm{T} 1$ & $203(24.2)$ & $144(24.5)$ & $59(23.5)$ & \\
\hline & $\mathrm{T} 2$ & $254(30.3)$ & $179(30.4)$ & 75 (29.9) & \\
\hline & T3 & $236(28.1)$ & $163(27.7)$ & $73(29.1)$ & \\
\hline
\end{tabular}


Table 1 Demographic, clinicopathological characteristics and treatment information of all, training and validation cohort (Continued)

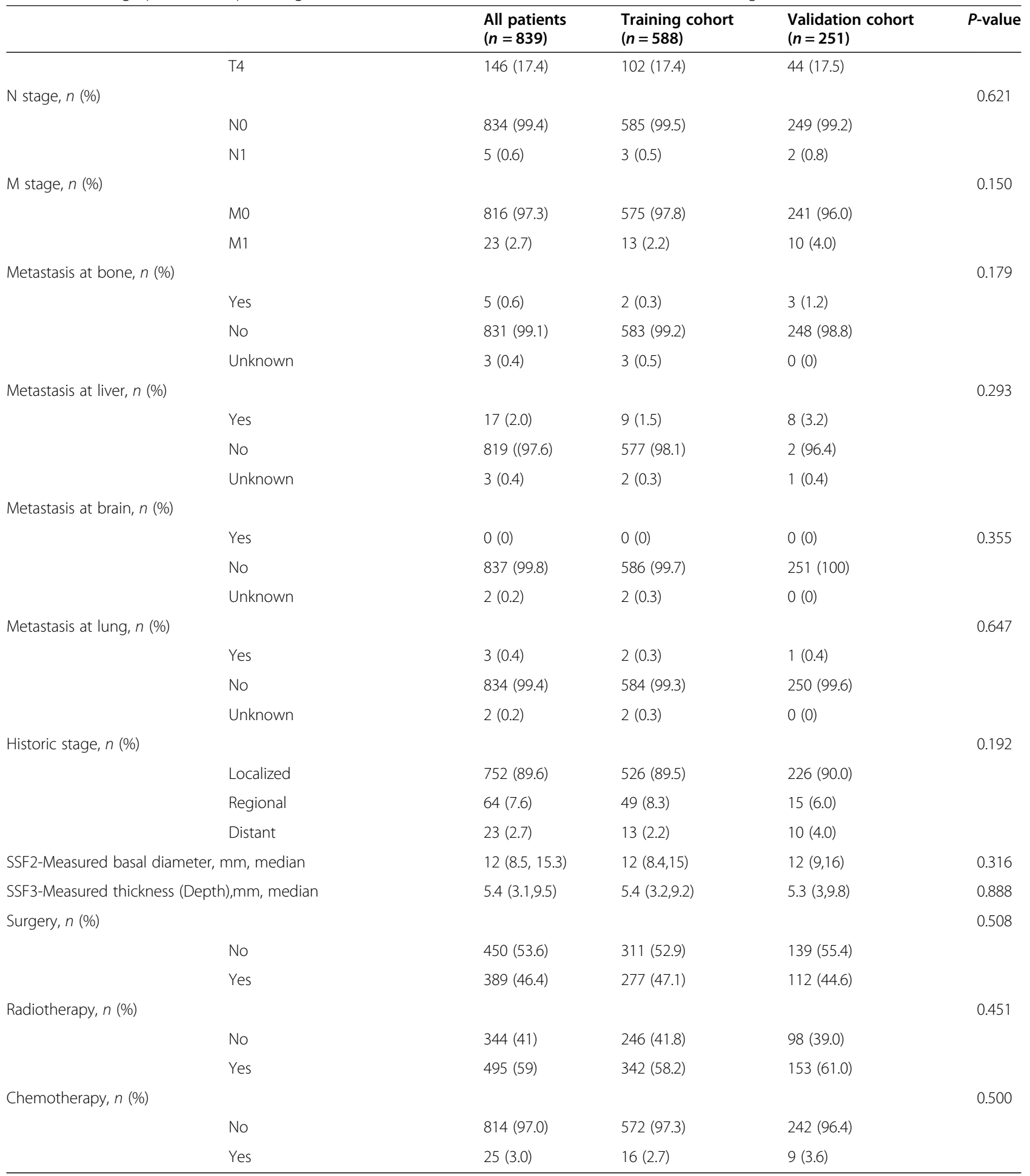

Independent prognostic factors in the training cohort To identify the prognostic factors associated with CSS in the training cohort, we used the univariate and multivariate analysis based on competing-risk models (Table 2). In univariate analysis, age $(P=0.001)$, primary site $(P=0.026)$, histological type $(P<0.001)$, T stage $(P<$ $0.001), \mathrm{N}$ stage $(P<0.001), \mathrm{M}$ stage $(P<0.001)$, surgery $(P<0.001)$, radiotherapy $(P<0.001)$ and chemotherapy $(P<0.001)$ were found to be significant prognostic factors. Multivariate analysis revealed that age $(P=0.003)$, 
Table 2 Univariate and multivariate analysis of factors's ability to predict CSS in the training cohort

\begin{tabular}{|c|c|c|c|c|c|}
\hline & & Univarable analysis & & Multivariate analysis & \\
\hline & & SHR $(95 \% \mathrm{Cl})$ & $P$-value & SHR $(95 \% \mathrm{Cl})$ & $P$-value \\
\hline Age & & & $0.001^{*}$ & & $0.003^{*}$ \\
\hline & $\leq 58$ & Ref & & Ref & \\
\hline & $>58$ & $1.748(1.256-2.433)$ & & $1.679(1.186-2.375)$ & \\
\hline Gender & & & 0.377 & & \\
\hline & Female & Ref & & & \\
\hline & Male & $1.150(0.844-1.567)$ & & & \\
\hline Race & & & 0.675 & & \\
\hline & White & Ref & & & \\
\hline & Black & $0.428(0.058-3.176)$ & & & \\
\hline & Other & $0.791(0.187-3.347)$ & & & \\
\hline Marriage & & & 0.563 & & \\
\hline & Married & Ref & & & \\
\hline & Unmarried & $1.074(0.771-1.495)$ & & & \\
\hline & Unknown & $1.330(0.786-2.253)$ & & & \\
\hline Insurance & & & 0.282 & & \\
\hline & Medicaid & Ref & & & \\
\hline & Insured & $0.726(0.422-1.250)$ & & & \\
\hline & Uninsured & $1.351(0.551-3.311)$ & & & \\
\hline & Unknown & $0.916(0.267-3.146)$ & & & \\
\hline Primary site & & & $0.026^{*}$ & & 0.247 \\
\hline & Chorioid & Ref & & Ref & \\
\hline & Cilliary body and iris & $1.568(1.055-2.331)$ & & $1.296(0.835-2.011)$ & \\
\hline Laterality & & & 0.569 & & \\
\hline & Left & Ref & & & \\
\hline & Right & $1.093(0.804-1.489)$ & & & \\
\hline Histological type & & & $<0.001^{*}$ & & \\
\hline & Spindle cell melanoma & Ref & & Ref & \\
\hline & $\begin{array}{l}\text { Mixed epithelioid and spindle } \\
\text { cell melanoma }\end{array}$ & 3.899 (2.014-7.547) & & $2.593(1.311-5.130)$ & $0.006^{*}$ \\
\hline & Epithelioid cell melanoma & 4.276 (1.924-9.504) & & $3.107(1.315-7.301)$ & $0.010^{*}$ \\
\hline & Other & $2.120(1.150-3.910)$ & & $2.128(1.093-4.142)$ & $0.026^{*}$ \\
\hline T stage & & & $<0.001^{*}$ & & \\
\hline & $\mathrm{T} 1$ & Ref & & Ref & \\
\hline & $\mathrm{T} 2$ & $1.478(0.749-2.917)$ & & $1.427(0.724-2.813)$ & 0.305 \\
\hline & $\mathrm{T} 3$ & 4.389 (2.394-8.045) & & $4.059(2.205-7.471)$ & $<0.001^{*}$ \\
\hline & T4 & $8.110(4.464-14.736)$ & & $5.135(2.675-9.856)$ & $<0.001^{*}$ \\
\hline N stage & & & $<0.001^{*}$ & & 0.666 \\
\hline & No & Ref & & Ref & \\
\hline & N1 & $10.163(3.565-28.969)$ & & $0.770(0.235-2.520)$ & \\
\hline M stage & & & $<0.001^{*}$ & & $<0.001^{*}$ \\
\hline & MO & Ref & & Ref & \\
\hline & M1 & $15.074(8.645-26.283)$ & & $11.531(5.115-25.992)$ & \\
\hline Surgery & & & $<0.001^{*}$ & & 0.961 \\
\hline
\end{tabular}


Table 2 Univariate and multivariate analysis of factors's ability to predict CSS in the training cohort (Continued)

\begin{tabular}{|c|c|c|c|c|c|}
\hline & & \multicolumn{2}{|c|}{ Univarable analysis } & \multicolumn{2}{|c|}{ Multivariate analysis } \\
\hline & & SHR (95\% Cl) & $P$-value & SHR (95\% Cl) & $P$-value \\
\hline & No & Ref & & Ref & \\
\hline & Yes & $1.869(1.366-2.556)$ & & $1.018(0.511-2.028)$ & \\
\hline \multirow[t]{3}{*}{ Radiotherapy } & & & $<0.001^{*}$ & & 0.479 \\
\hline & No & Ref & & Ref & \\
\hline & Yes & $0.512(0.376-0.698)$ & & $0.776(0.385-1.565)$ & \\
\hline \multirow[t]{3}{*}{ Chemotherapy } & & & $0.023^{*}$ & & 0.213 \\
\hline & No & Ref & & Ref & \\
\hline & Yes & $2.301(1.119-4.731)$ & & $0.512(0.179-1.467)$ & \\
\hline
\end{tabular}

${ }^{*} P<0.05$

histological type $(P=0.006)$, $\mathrm{T}$ stage $(P<0.001)$ and $\mathrm{M}$ stage $(P<0.001)$ were independent prognostic factors to predict CSS of UM.

\section{Prognostic nomogram for cancer-specific survival of uveal} melanoma

All independent prognostic factors were included to develop a nomogram to calculate the 3-year and 5year CSS probabilities (Fig. 2). From the nomogram, $\mathrm{T}$ stage was found the most predominant contributor to the prognosis. Each subtype within these four significant independent variables was assigned a score on the point scale. The total scores of independent prognostic factors projected to the bottom scale represent the probabilities of 3- and 5-year CSS.

\section{Calibration and validation of the nomogram}

Our nomogram was tested by 500 bootstrap resamples for the internal validation with the training cohort, as well as the external validation with the validation cohort. Calibration plot for predicting 3- and 5-year CSS of UM demonstrated a good agreement between the predicted and actual CSS probabilities in both the internal and external validations (Fig. 3). The Harrell's C-index for this model was 0.778 (95\% CI:0.756-0.800) and 0.786 (95\% CI: $0.749-0.816)$ in the training cohort and validation cohort. We performed ROC curves to verify accurate predictability for 1-, 3- and 5-year CSS. Areas under the curve (AUCs) were 0.814, 0.771, and 0.792 in the training cohort, $0.788,0.781$ and 0.804 in the validation cohort, respectively (Fig. 4). The nomogram was

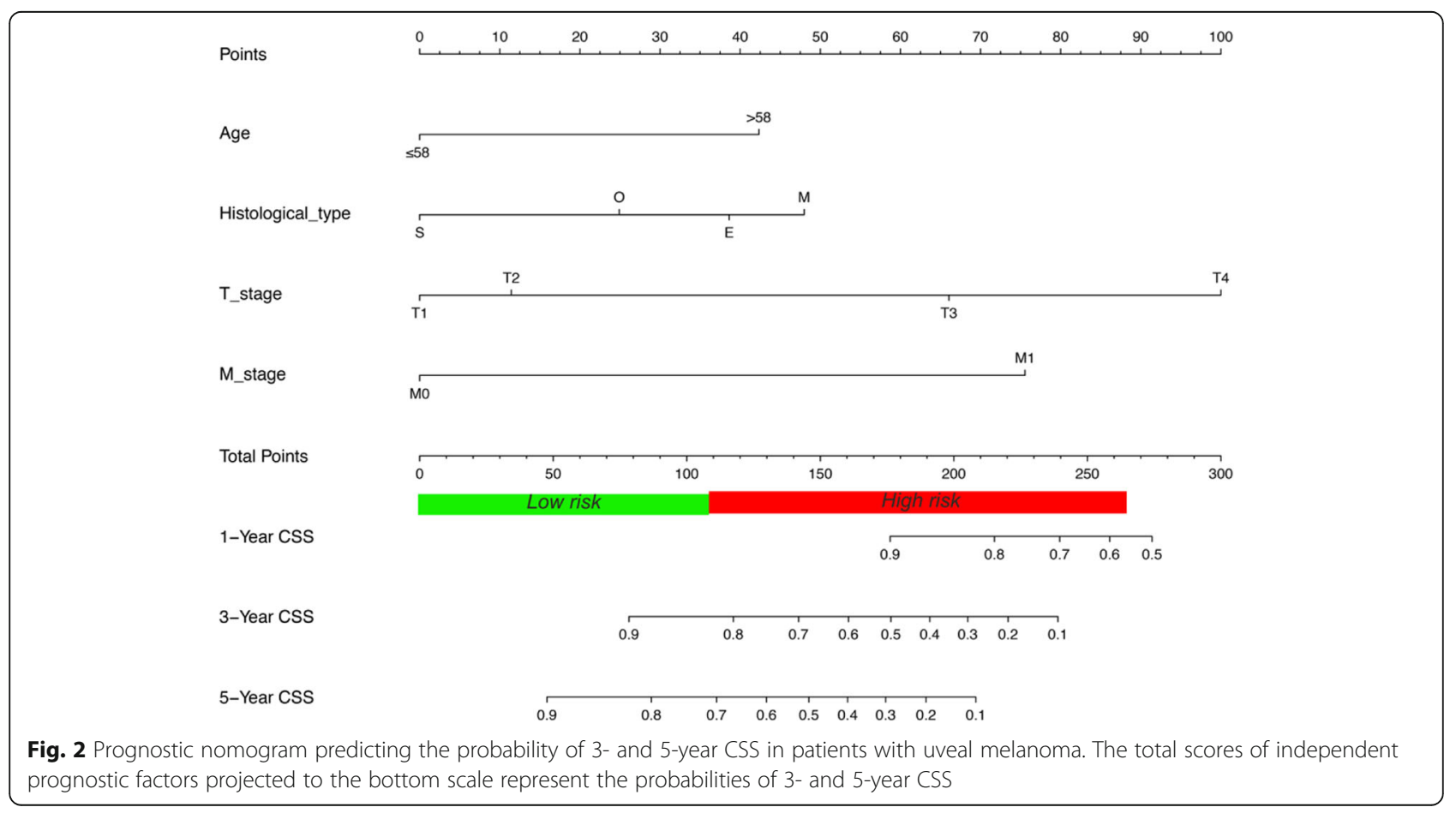



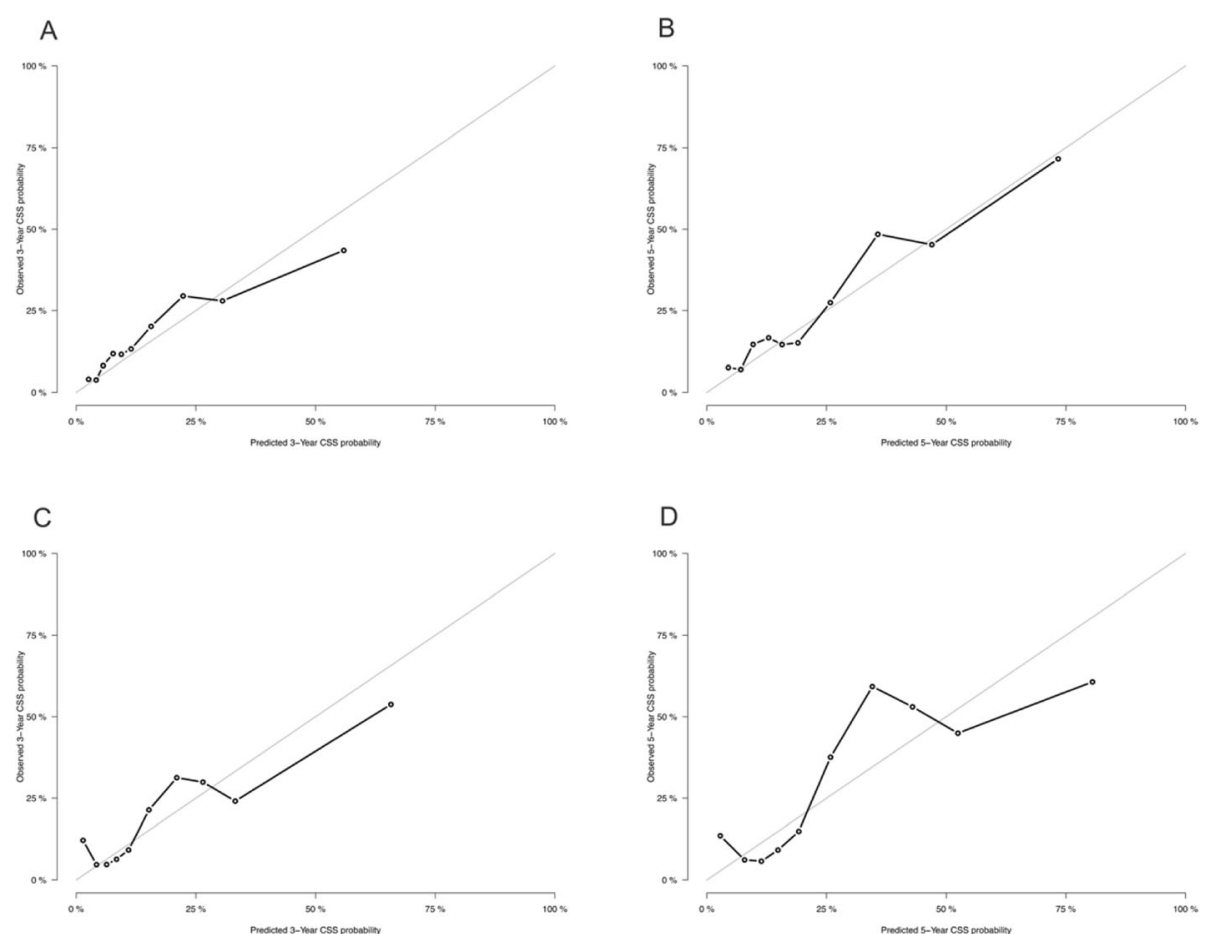

Fig. 3 The calibration curves for predicting CSS in the training cohort $\mathbf{a}, \mathbf{b}$ and validation cohort $\mathbf{c}$, $\mathbf{d}$ at the time point of 3 and 5 years respectively. Nomogram-predicted probability is plotted on the $x$-axis; actual probability is plotted on the $y$-axis

programmed into an online calculator, which is available at https://zengqiaozhu123.shinyapps.io/UM_prognosis/.

\section{Nomogram performance in risk group stratification}

Consistent with some previous studies, the cut-off value was determined from top one-third of the total scores of patients in the training cohort calculated from the nomogram. Patients were classified into low risk $(n=$ $388,66.0 \%$, score $<108)$ and high risk $(n=200,34.0 \%$, score $\geq 108$ ) groups. Distinct cumulative incidence curves of UM cancer-specific mortality were depicted in the training and validation cohorts (Fig. 5).

Patients treated with surgery, radiation or chemotherapy were categorized into the high-risk and low-risk groups (Fig. 6). For surgery, in high-risk groups, no significant difference in cancer specific mortality was found between surgery and no surgery; while in low-risk group, surgery could statistically reduce the mortality (SHR $0.478,95 \%$ CI $0.275-0.831, P=0.009$ ). For radiation, there was no difference in cancer specific mortality between radiation and no radiation in the high-risk or low-risk groups. In terms of chemotherapy, there was also no difference in cancer specific mortality between chemotherapy and no chemotherapy in the high-risk or low-risk groups, indicating that the nomogram appears to be able to differentiate patients with a different risk. In addition, we compared the cancer specific mortality of patients with different AJCC stage of 2 and 3 in different risk groups. In low-risk or high-risk group, there was no difference in mortality between patients with AJCC stage 2 and 3; while high-risk group presented with higher cancer specific mortality than lowrisk group regardless of the AJCC stage (Fig. 7).

The NRI value in AJCC staging system was -0.153 (95\% CI $-0.29--0.041)$ for 3 years of follow-up and 0.276 ( $95 \%$ CI $-0.415--0.132$ ) for 5 years of follow-up. These results indicate that our new model exhibited markedly superior predictive performance compared to the AJCC model. Similarly, the IDI values for 3 and 5 years of follow-up in the AJCC staging system were $0.021(P=0.076)$ and $-0.045(P=0.004)$, respectively.

\section{Discussion}

$\mathrm{UM}$ is a rare but aggressive intraocular malignancy. Despite advances in the local treatment methods for primary UM, the survival rates have not improved [14]. To date, there was no available prognosis prediction model for UM, especially model of CSS. Herein, we developed and validated a personalized nomogram predicting the CSS of UM patients, using a large SEER cohort. Our results supported the satisfactory performance of the nomogram in UM prognosis prediction, and compared it with AJCC staging system. The patients stratified into different risk groups demonstrated distinct cancer-specific mortality curves within respective therapies. 


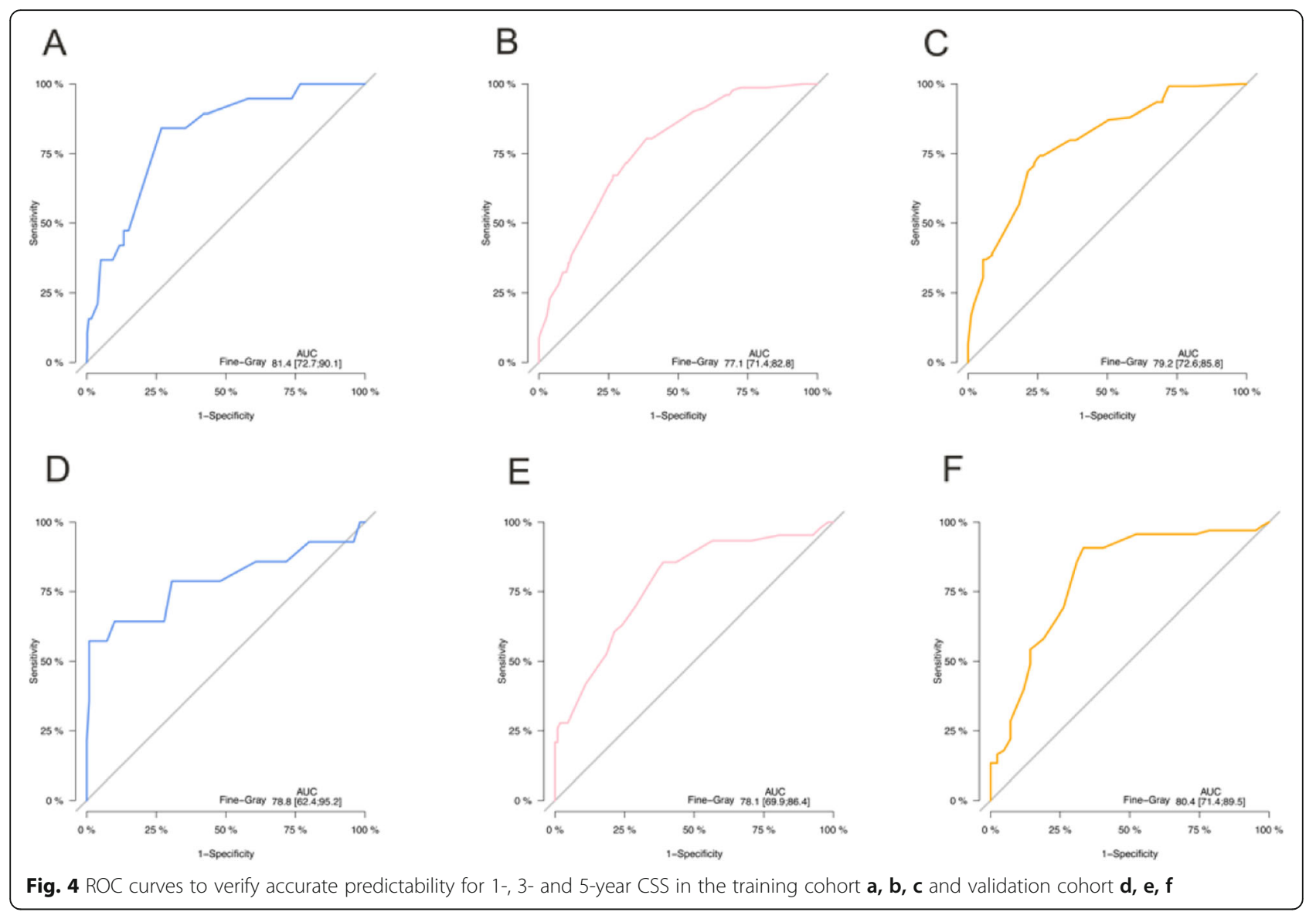

There have been numerous factors identified to predict overall survival of UM, including clinical features (tumor size), histopathological features (epithelioid cell type, mitotic activity, HLA expression, tumor infiltration by proangiogenic M2-macrophages and lymphocytes, microvascular loops and networks, and extracellular matrix patterns), cytogenetic features (abnormalities on chromosomes 3, 6, 8 and 1) and etc. [15]. Xu et al. investigated the SEER database (2010-2015) and found that determinants of overall survival and CSS included age at diagnosis, AJCC stage, and radiation therapy [16]. Similarly, in Mahendraraj et's study based on SEER database (1973-2012), it was proposed that male sex, older age, distant disease, and primary surgical therapy rather than
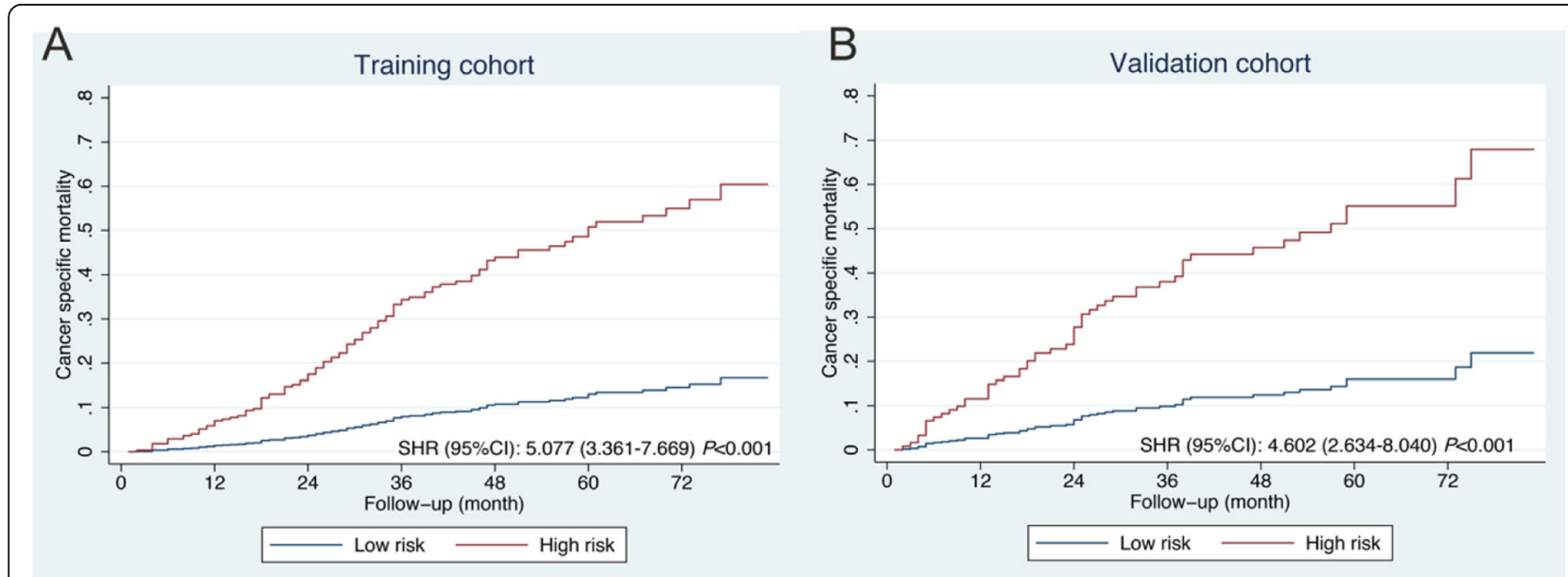

Fig. 5 Cumulative incidence curves of UM cancer-specific mortality in the training $\mathbf{a}$ and validation $\mathbf{b}$ cohorts 


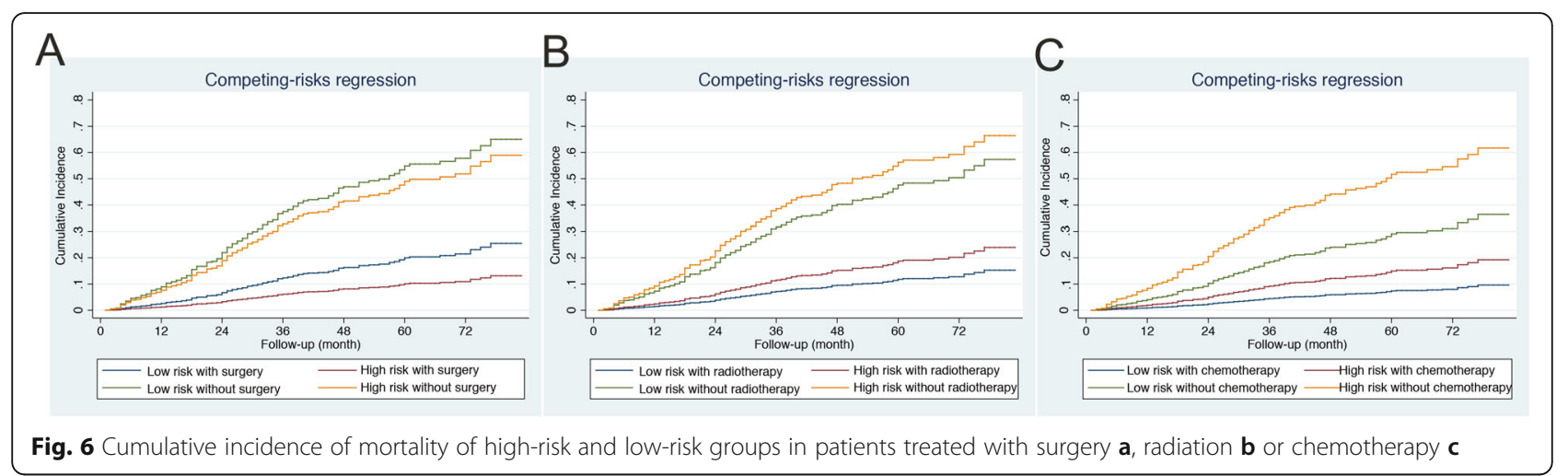

radiotherapy are associated with an increased risk of mortality [17]. The compare and contrast table of different studies about the UM prognosis based on SEER database were indicated in Supplementary Table 1. In a retrospective study incorporating $171 \mathrm{UM}$ patients by Yue et al., a large basal tumor diameter, ciliary body involvement, non-spindle cell type, extrascleral extension, and negative BAP1 staining were risk factors for the prediction of UM prognosis [18]. Coleman et al. also found that a combination of cell type, glaucoma, and largest tumor diameter had strong and independent prognostic significance for UM [19]. In some larger cohorts, it was proposed that older age at diagnosis and male gender were correlated with increased mortality [20-23]. However, almost all of those studies were in the method of Cox regression to investigate the OS or CSS, with relatively limited sample sizes. Consistent with previous findings, our results showed that age, $\mathrm{T}$ stage categories, $\mathrm{M}$ stage categories, and the histological types were independent prognostic factors to predict CSS of the patients with UM. In univariate analysis, radiotherapy was a protective factor for CSS. Conversely, surgery and chemotherapy were found to be risk factors for CSS. We speculated that patients receiving surgery or chemotherapy might have been burdened with more severe condition, and heterogeneity of inclusion criteria, methods/types of surgeries or chemotherapies in different institutions may explain for the result. We observed no statistical significance of surgery, radiotherapy or chemotherapy in the multivariate analysis. In addition, although the AJCC staging system is a significant predictive tool for the prognosis of UM, it lacks of some

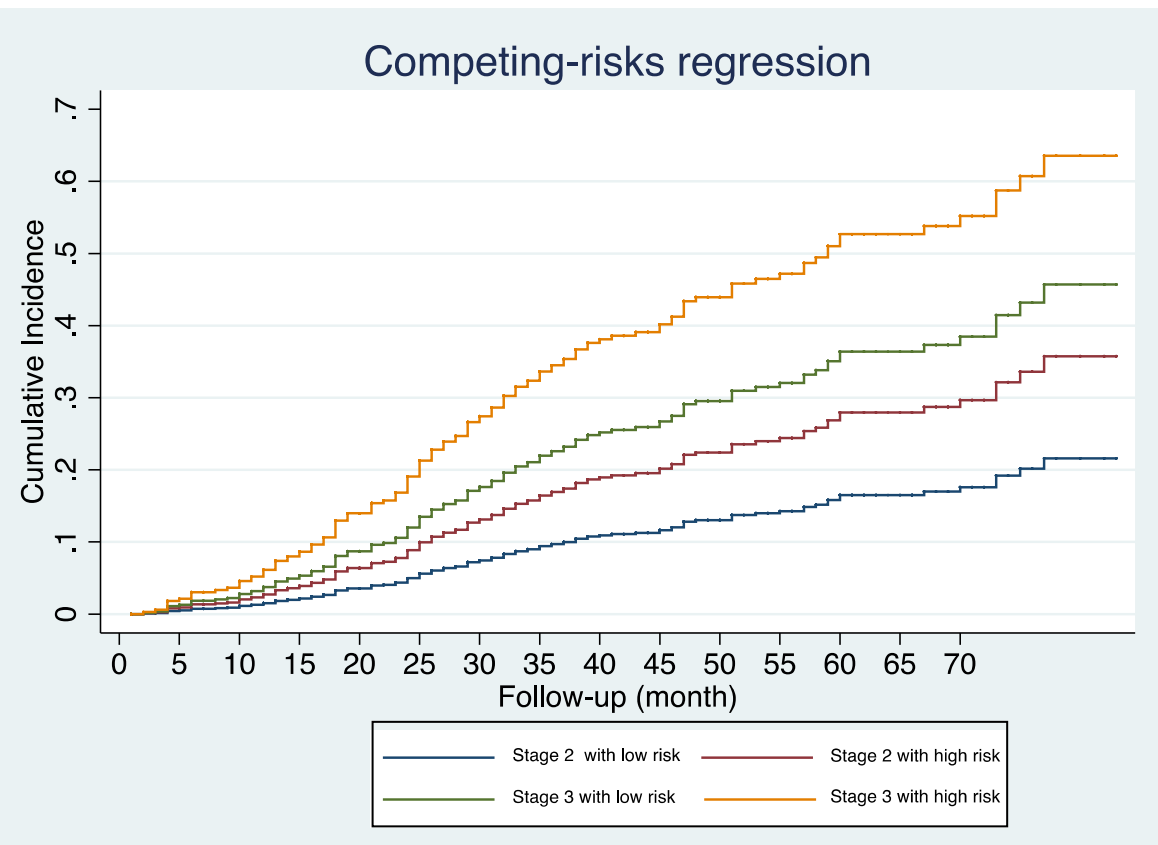

Fig. 7 Cancer specific mortality of patients with different AJCC stage of 2 and 3 in different risk groups 
important risk factors such as age, sex, and marital status. To our knowledge, our study first built a nomogram to predict CSS of UM, which may act as a supplement to the prognosis of UM using the AJCC staging system. The constructed nomogram exhibited good discrimination and calibration, with C-index and AUC of more than 0.7 .

Based on our nomogram, we developed a risk classification system that excellently classified patients with UM into high- and low-risk of cancer-specific death. In low-risk group, surgery could statistically reduce the mortality, suggesting the significant positive impact of surgery on patients with low risk. For radiation/chemotherapy, no difference in cancer specific mortality was found between radiation/chemotherapy and no radiation/chemotherapy whether in the high-risk or low-risk groups, indicating that patients were categorized into distinct risk groups regardless of the treatment. With limited information on detailed treatment from SEER database, we should cautiously interpret the influence of different therapies on prognosis. Management of UM mostly depends on the site, size of tumor and local extension [24], Treatment aims at preserving the eye and useful vision and preventing metastases. In USA, there has been a trend from local resection and enucleation into radiotherapy [14]. However, the long-term vision loss of radiation is still inevitable. For metastatic UM, liver-directed therapy and systemic therapy (chemotherapy, immunotherapy, targeted therapy) have been utilized. Besides, a lot of advanced approaches are currently under research, such as selumetinib, tebentafusp and etc. From the biological view, prevention and/or treatment should be based on the specific mutation of the tumor of the patients in the future. Further prospective large studies are required to investigate the impact of novel treatments on UM patients [25].

Regardless of the AJCC stage, high-risk group presented with higher cancer specific mortality than low-risk group, indicating that our model appears to be able to efficiently differentiate patients with a different risk. Moreover, we introduced two indexes of NRI and IDI. NRI reflects how the nomogram reclassifies the risk probabilities better than the AJCC staging system, and IDI indicates the improvement in the ability of the nomogram to distinguish between AJCC stages. Compared with AJCC staging system, our new model exhibited markedly superior predictive performance. Considering our model couldn't incorporate all prognostic factors for clinical decision, more clinical researches were needed to validate its applicability.

Meanwhile, there are several limitations in our study. First, the retrospective nature of SEER-based study may bring about biases. Some crucial data, including lymphovascular invasion, detailed information of the tumor, detailed treatment approaches, some relevant molecular or cytogenetic factors and information of the 8th edition of AJCC staging system were not available, restricting further analysis. Cytogenetic studies are currently at the forefront of uveal melanoma management. In our clinical practice, it is not easy to obtain cytogenetic data, which requires more investment and support. We will take this indicator and more other factors into consideration in our further research, to construct a more advanced prediction model. Additionally, we could not neglect the geographical bias of the nonuniform distribution of the SEER registries, including the race heterogeneity. Second, because of the low disease prevalence, the cohort was relatively small. Larger sample sizes are necessary for further independent validation and prognostic stratification analysis. Third, we only included patients with complete information, which would have introduced selection bias. Finally, although our nomogram and risk classification system were constructed and validated in two independent subgroups from the SEER database, external validation with other populations is still warranted.

\section{Conclusions}

In conclusion, we have developed and validated a competing risk nomogram to reliably predict cancer-specific survival of patients with UM, of which the prognostic value was better than that of the AJCC staging system alone. This convenient tool may be useful for evaluating cancer-specific prognosis, identifying patients with highrisk of cancer-specific death and clinical decision making. Future external validation and larger prospective studies are still required.

\section{Abbreviations \\ UM: Uveal melanoma; CSS: Cancer-specific survival; SEER: The Surveillance, Epidemiology, and End Results database; C-index: Harrell's concordance index; ROC curve: Receiver operating characteristic curve; IDI: Integrated discrimination improvement; NRI: The net reclassification improvement; AJCC: The American Joint Committee on Cancer; AUCs: Areas under the curve; SHR: Subhazard ratio; CIF: Cumulative incidence functions; \\ IQR: Interquartile range}

\section{Supplementary Information}

The online version contains supplementary material available at https://doi. org/10.1186/s12886-021-01968-6.

Additional file 1: Supplementary Table 1. The compare and contrast table of different studies about the UM prognosis based on SEER database.

\section{Acknowledgements} Not applicable.

Authors' contributions

Study design and concept (Q.Z., Y.Y., M.Z.); database search (Q.Z., Y.Y., M.Z.); data extracting (Q.Z., Y.Y., M.Z.); data analysis (Q.Z., Y.Y.); manuscript writing (Q.Z.). The authors read and approved the final manuscript. 
Funding

Not applicable.

\section{Availability of data and materials}

The data were abstracted from an open database, the Surveillance, Epidemiology, and End Results (SEER) database (https://seer.cancer.gov). Data described in the manuscript, accession number, and password will be made available by the corresponding author upon request.

\section{Declarations}

\section{Ethics approval and consent to participate}

This article does not contain any studies with human participants or animals performed by any of the authors.

\section{Consent for publication}

Not applicable.

\section{Competing interests}

The authors declare that they have no conflict of interest.

Received: 28 January 2021 Accepted: 21 April 2021

Published online: 25 May 2021

\section{References}

1. Singh AD, Turell ME, Topham AK. Uveal melanoma: trends in incidence, treatment, and survival. Ophthalmology. 2011;118(9):1881-5. https://doi. org/10.1016/j.ophtha.2011.01.040.

2. Chang AE, Karnell LH, Menck HR. The National Cancer Data Base report on cutaneous and noncutaneous melanoma: a summary of 84,836 cases from the past decade. The American College of Surgeons Commission on Cance and the American Cancer Society. Cancer. 1998;83(8):1664-78. https://doi. org/10.1002/(SICl)1097-0142(19981015)83:8<1664":AID-CNCR23>3.0.CO;2-G

3. Kujala E, Mäkitie T, Kivelä T. Very long-term prognosis of patients with malignant uveal melanoma. Invest Ophthalmol Vis Sci. 2003;44(11):4651-9. https://doi.org/10.1167/iovs.03-0538.

4. Aronow ME, Topham AK, Singh AD. Uveal melanoma: 5-year update on incidence, treatment, and survival (SEER 1973-2013). Ocul Oncol Pathol. 2018;4(3):145-51. https://doi.org/10.1159/000480640.

5. Edge SB, Compton CC. The American joint committee on Cancer: the 7th edition of the AJCC cancer staging manual and the future of TNM. Ann Surg Oncol. 2010;17(6):1471-4. https://doi.org/10.1245/s10434-010-0985-4

6. Finger PT. 7th edition, AJCC-UICC ophthalmic oncology task force. The 7th edition AJCC staging system for eye cancer: an international language for ophthalmic oncology. Arch Pathol Lab Med. 2009;133(8):1197-8. https://doi. org/10.5858/133.8.1197.

7. Zeng Y, Mayne N, Yang CJ, D'Amico TA, Ng CSH, Liu CC, et al. AME thoracic surgery collaborative group. A Nomogram for predicting Cancer-specific survival of TNM 8th edition stage I non-small-cell lung Cancer. Ann Surg Oncol. 2019;26(7):2053-62. https://doi.org/10.1245/s10434-019-07318-7.

8. Tang X, Zhou X, Li Y, Wang Y, Huang M, Ren L, et al. A novel Nomogram and risk classification system predicting the Cancer-specific survival of patients with initially diagnosed metastatic esophageal Cancer: a SEERbased study. Ann Surg Oncol. 2019;26(2):321-8. https://doi.org/10.1245/s1 0434-018-6929-0.

9. Fine JP, Gray RJ. A proportional hazards model for the subdistribution of a competing risk. J Amer statist Assoc 94: 496-509. J Am Stat Assoc. 1999; 94(446):496-509. https://doi.org/10.1080/01621459.1999.10474144.

10. Fine JP. Regression modeling of competing crude failure probabilities. Biostatistics. 2001;2(1):85-97. https://doi.org/10.1093/biostatistics/2.1.85

11. Frank H. Regression Modeling Strategies with Applications to Linear Models, Logistic Regression and Surviva I Analysis. New York: Springer; 2015.

12. Iasonos A, Schrag D, Raj GV, Panageas KS. How to build and interpret a nomogram for cancer prognosis. J Clin Oncol. 2008;26(8):1364-70. https:// doi.org/10.1200/JCO.2007.12.9791.

13. Cook NR. Comments on 'Evaluating the added predictive ability of a new marker: from area under the ROC curve to reclassification and beyond' by M. J. Pencina et al., statistics in medicine. Stat Med. 2008;27(2):191-5. https:// doi.org/10.1002/sim.2987.
14. Singh $A D$, Topham A. Survival rates with uveal melanoma in the United States: 1973-1997. Ophthalmology. 2003;110(5):962-5. https://doi.org/10.101 6/S0161-6420(03)00077-0.

15. Chattopadhyay C, Kim DW, Gombos DS, Oba J, Qin Y, Williams MD, et al. Uveal melanoma: from diagnosis to treatment and the science in between. Cancer. 2016;122(15):2299-312. https://doi.org/10.1002/cncr.29727.

16. Xu Y, Lou L, Wang Y, Miao Q, Jin K, Chen M, et al. Epidemiological study of Uveal Melanoma from US surveillance, epidemiology, and end results program (2010-2015). J Ophthalmol. 2020:3614039.

17. Mahendraraj K, Lau CS, Lee I, Chamberlain RS. Trends in incidence, survival, and management of uveal melanoma: a population-based study of 7,516 patients from the surveillance, epidemiology, and end results database (1973-2012). Clin Ophthalmol. 2016;10:2113-9. https://doi.org/10.2147/OPTH. S113623.

18. Yue H, Oian J, Yuan Y, Zhang R, Bi Y, Meng F, et al. Clinicopathological characteristics and prognosis for survival after Enucleation of Uveal melanoma in Chinese patients: long-term follow-up. Curr Eye Res. 2017; 42(5):759-65. https://doi.org/10.1080/02713683.2016.1245422.

19. Coleman K, Baak JP, Van Diest P, Mullaney J, Farrell M, Fenton M. Prognostic factors following enucleation of 111 uveal melanomas. Br J Ophthalmol. 1993;77(11):688-92. https://doi.org/10.1136/bjo.77.11.688.

20. Virgili G, Gatta G, Ciccolallo L, Capocaccia R, Biggeri A, Crocetti E, et al. Paci E; EUROCARE working group. Survival in patients with uveal melanoma in Europe. Arch Ophthalmol. 2008;126(10):1413-8. https://doi.org/10.1001/a rchopht.126.10.1413

21. Burr JM, Mitry E, Rachet B, Coleman MP. Survival from uveal melanoma in England and Wales 1986 to 2001. Ophthalmic Epidemiol. 2007;14(1):3-8. https://doi.org/10.1080/09286580600977281.

22. Bergman L, Seregard S, Nilsson B, Ringborg U, Lundell G, Ragnarsson-Olding B. Incidence of uveal melanoma in Sweden from 1960 to 1998. Invest Ophthalmol Vis Sci. 2002;43(8):2579-83.

23. Isager $\mathrm{P}$, Engholm G, Overgaard J, Storm H. Uveal and conjunctival malignant melanoma in Denmark 1943-97: observed and relative survival of patients followed through 2002. Ophthalmic Epidemiol. 2006;13(2):85-96. https://doi.org/10.1080/09286580600553330

24. Jovanovic P, Mihajlovic M, Djordjevic-Jocic J, Vlajkovic S, Cekic S, Stefanovic V. Ocular melanoma: an overview of the current status. Int J Clin Exp Pathol. 2013;6(7):1230-44

25. Smit KN, Jager MJ, de Klein A, Kiliç E. Uveal melanoma: towards a molecular understanding. Prog Retin Eye Res. 2020;75:100800. https://doi.org/10.1016/j. preteyeres.2019.100800.

\section{Publisher's Note}

Springer Nature remains neutral with regard to jurisdictional claims in published maps and institutional affiliations.

Ready to submit your research? Choose BMC and benefit from:

- fast, convenient online submission

- thorough peer review by experienced researchers in your field

- rapid publication on acceptance

- support for research data, including large and complex data types

- gold Open Access which fosters wider collaboration and increased citations

- maximum visibility for your research: over $100 \mathrm{M}$ website views per year

At $\mathrm{BMC}$, research is always in progress.

Learn more biomedcentral.com/submissions 